\title{
Managing anxiety associated with neurodegenerative disorders
}

\author{
Brian P. Gomoll* and Anand Kumar
}

\author{
Address: Department of Psychiatry, University of Illinois at Chicago, 912 South Wood Street, Chicago, IL, 60612, USA \\ * Corresponding author: Brian P. Gomoll (bpgomoll@gmail.com) \\ Fl000Prime Reports 2015, 7:05 (doi:10.12703/P7-05) \\ All Fl000Prime Reports articles are distributed under the terms of the Creative Commons Attribution-Non Commercial License \\ (http://creativecommons.org/licenses/by-nc/3.0/legalcode), which permits non-commercial use, distribution, and reproduction in any medium, \\ provided the original work is properly cited. \\ The electronic version of this article is the complete one and can be found at: http://fl000.com/prime/reports/m/7/5
}

\begin{abstract}
Anxiety is a common symptom among patients with cognitive impairment. The presence of anxiety is correlated with poorer outcomes; despite this, there is limited research on anxiety related to neurodegenerative disorder. In this article, we discuss the prevalence of anxiety and factors involved in the etiology of anxiety in patients with diagnosed neurodegenerative disorders and related states of cognitive impairment as well as the evidence for currently available methods of evaluating and treating these symptoms. Specific treatments are highlighted in light of current evidence, followed by a discussion of the difficulties inherent in the study and treatment of anxiety in this population.
\end{abstract}

\section{Introduction}

Anxiety is a common symptom among patients with cognitive impairment, occurring in a majority of patients with dementia of the Alzheimer's disease (AD) type [1] and $10 \%$ to $45 \%$ of patients with mild cognitive impairment (MCI) [2,3]. It is the third most common neuropsychiatric symptom of MCI [4], and there is some indication that the presence of anxiety in MCI increases the risk of progressing to $\mathrm{AD}$ [5-7]. Neuropsychiatric symptoms (including anxiety, depression, psychosis, and agitation) are often the first signs of cognitive disorders and are correlated with faster progression to dementia $[4,8]$. Anxiety is often comorbid with non-AD dementias, particularly frontotemporal dementia, semantic dementia, and non-fluent aphasia $[9,10]$. The presence of anxiety has also been correlated with disability in social functioning independent of age [11]. Treatment remains difficult in these populations because of increased medical comorbidities, medication interactions, and cognitive side effects.

\section{Underlying factors and pathophysiology of anxiety in neurocognitive disorders}

Anxiety in patients with neurodegenerative disorders involves multifaceted and variable factors. Adding to this difficulty, anxiety is a general term that encompasses multiple symptoms and syndromes, and studies differ on criteria used. Patients with neurodegenerative disorders who present with symptoms of anxiety often have multiple potentially contributory medical comorbidities or possible underlying primary anxiety disorder (or both) prior to diagnosis of a neurodegenerative condition. Thus, both studying the pathophysiology of anxiety in neurocognitive disorders and applying the results of such studies to the care of patients are often difficult.

Anxiety is a consequence of multiple underlying and overlapping factors, including environment, physical state, underlying brain disease, heightened vulnerability due to age and cognitive decline, and psychological/existential issues. Biologically, anxiety is often conceptualized as a complex interaction between multiple systems within the brain, including the prefrontal cortex, amygdala, ascending norepinephrine and serotonergic pathways, and the hypothalamic-pituitary-adrenal axis among other systems involved in emotional processing, fear conditioning, and memory [12-15]. There is limited evidence as to the pathophysiology of increased anxiety in the specific context of neurodegeneration; the bilateral entorhinal cortex, amygdala, anterior parahippocampal gyri, left superior temporal gyrus, and insula have been implicated as playing a role in anxiety in the $\mathrm{AD}$ population [16-18], as has the salience network [19]. Anxiety is also frequently encountered in non- $\mathrm{AD}$ neurocognitive disorders, although the pathophysiology of anxiety in these conditions is even less 
studied. Anxiety is also frequently comorbid with depression in this population [20], although any evidence for treatment of comorbid anxiety and depression in this population is limited to treatment of depression.

\section{Evaluation of anxiety in neurodegenerative disorders Initial symptoms}

Signs and symptoms such as anxious or worried appearance, fearfulness, restlessness, tension, fidgeting, and sleep disturbance are non-specific, making a clear diagnosis of anxiety difficult $[1,20]$. As anxiety has a large cognitive component, it may be difficult to diagnose in patients with neurocognitive disorders. Comorbid medical conditions, particularly in patients with impaired communication skills, need to be evaluated with appropriate history, physical exam, and laboratory/imaging work-up. Anxiety can also manifest as agitation and aggression, particularly in patients with impaired communication or insight into their conditions. Interestingly, some studies suggest that greater insight into a diagnosis of dementia is correlated with increased anxiety and depression but that decreased insight is correlated with apathy [21].

\section{Approach to evaluation}

There are multiple ways to approach neuropsychiatric symptoms. In a recent article, a multidisciplinary panel suggests the "DICE" approach of describe, investigate, collaborate, and evaluate [22]. Using a behavioral approach, caregivers are asked to identify antecedents, specific behaviors, and consequences, followed by investigation into patient, caregiver, environmental, and cultural factors that could have contributed to the problem. This is followed by creation of an appropriate treatment plan based on behavioral interventions and appropriate treatment of physical concerns. Although this approach is likely to be used more in disruptive behaviors than anxiety, the behavioral basis could be helpful for anxiety, especially in a population that has decreased communicative ability.

One concern about such an approach is that caregivers can have a negative bias and over-report symptoms, particularly if the caregiver's own health is impaired [23]. Therefore, continued informed assessment by a clinician remains essential. As a first step in approaching the patient, appropriate history, mental status examination, physical examination, and diagnostic work-up are important to look for signs of endocrine (including thyroid, hypoglycemia, and pheochromocytoma), cardiovascular (tachycardia, arrhythmias, and anemia), respiratory (asthma, pneumonia, and hyperventilation), neurologic (seizures and focal syndromes), or other conditions contributing to or mimicking anxiety $[24,25]$. Substances must also be considered, particularly symptoms of alcohol withdrawal, intoxication with drugs of abuse, and anxiogenic medications. Although a full review of medical conditions and substances that can cause or mimic anxiety is beyond the scope of this article, it is important to review the list of medications (including over-the-counter medications, supplements, caffeine, recreational substances, and herbal treatments), which may have direct anxiogenic effects or cause symptoms that are similar to the symptoms of anxiety. If the patient has a known illness that can contribute to anxiety, such as asthma, or has been taking medications that can cause anxiety (such as sympathomimetics), then consideration should first go toward managing those conditions or medications. Although evidence is limited, there is some indication that certain "medical mimics" of anxiety may be experienced differently than primary anxiety; for example, one study indicated that patients with pheochromocytoma experienced symptoms similar to anxiety but without the severe apprehension, fear, or agoraphobia of patients with primary anxiety disorders [26]. However, such a distinction is made more difficult by patients with neurocognitive disorders, who may not be able to adequately explain their inner experiences.

Clinicians can use a behavioral-based method similar to the components in the DICE approach, first exploring both the symptoms and the context, then considering comorbidities, possible explanations, and contributing/ reinforcing medical, environmental, and cultural factors. To increase recognition and diagnosis, multiple scales have also been used to determine neuropsychiatric symptoms in patients with cognitive impairment, including the behavioral pathology in AD (BEHAVE$\mathrm{AD})$, neuropsychiatric inventory (NPI), behavioral rating scale, and the NPI-clinician rating scale (NPI-C) [4]. These scales are useful for identification of potential anxiety, although their utility in choosing an appropriate treatment is unclear.

\section{Treatment to overview}

We will briefly review common treatments for anxiety in individuals with diagnosed cognitive impairment. This does not include treatment of underlying conditions that present as anxiety, which is a large topic beyond the scope of this review. A common theme during this discussion is lack of good data for use in the cognitively impaired population, especially in regard to pharmacologic approaches; similarly, there is a clear lack of adequate understanding of how each pharmacologic target is related to the underlying pathophysiology of neurodegenerative disorders. 


\section{Pharmacologic approaches \\ Antidepressants}

Antidepressants, as a general class, have been used for depression in the setting of neurodegenerative disorders, though with some controversy in regard to their efficacy [27]; evidence of their efficacy for anxiety in this population is even less strong [4]. As with cognitively intact patients, serotonergic depressants are the most studied for anxiety. Although data are limited, selective serotonin reuptake inhibitors (SSRIs) and serotonin norepinephrine reuptake inhibitors can be considered valid options for treatment, especially since they do not have many of the problems associated with other anxiolytics and have been found to be efficacious in those with anxiety disorders without dementia. However, it is important to note that many of the tricyclics are listed in the Beers List (Beers Criteria for Potentially Inappropriate Medication Use in Older Adults) as "avoid" because of their anticholinergic and sedating properties [28].

\section{Benzodiazepines}

Benzodiazepines have limited use in the older or cognitively impaired population because of cognitive side effects, increased risks of falls, paradoxical agitation, and tolerance $[29,30]$. All benzodiazepines are listed on the Beers List as "avoid" for agitation and insomnia, and it is noted that smaller doses may be as effective and safer in the older population [28]. When used, benzodiazepines should be used at low doses in a time-limited fashion and with close follow-up and monitoring.

\section{Cholinesterase inhibitors}

There have been limited but encouraging data on the effect of cholinesterase inhibitors on behavioral symptoms of neurodegenerative disorders, including anxiety [31]. A few trials have indicated that donepezil may have some beneficial effect on anxiety and agitation [32]. Rivastigmine was found to have improvement in anxiety in one open-label observational study [33], although other studies report improvement in functioning but with noticeable side effects [34]. Galantamine has been associated with improved functioning and behavior, although effects on anxiety itself have not been reported $[35,36]$. Cholinesterase inhibitors are also frequently used for neuropsychiatric symptoms associated with dementia with Lewy bodies because of prominent cholinergic deficits, although it is unclear whether this would be helpful for anxiety specifically $[37,38]$.

\section{Memantine}

Memantine is an antagonist of N-methyl-D-aspartate (NMDA) receptors approved for treatment of moderate to severe dementia. It has been shown to have some possible anxiolytic effects in mice models and has been suggested as an adjunctive treatment for mood and anxiety disorders, but with disappointing results thus far $[39,40]$. There are limited data on its effect on anxiety when used for dementia.

\section{Buspirone}

Buspirone is an anxiolytic medication that is a partial agonist at the serotonin $5 \mathrm{HT}_{1 \mathrm{~A}}$ receptor; it is also an antagonist at the dopamine D2 autoreceptor and may have weak affinity to $5 \mathrm{HT}_{2}$ receptors. Its benefits include a low potential for dependence and many of the side effects of benzodiazepines, and it has shown some benefit in the behavioral disturbances in neuropsychiatric conditions $[41,42]$. There are some reports of anxiolytic effect in dementia, although most evidence is in patients with agitation [41,43].

\section{Melatonin}

Melatonin is a pineal-secreted neurohormone that is important for maintenance of a normal circadian rhythm. It is frequently used for sleep, although a recent Cochrane review concludes that evidence for efficacy in $\mathrm{AD}$ is limited [44]. Melatonin receptor type 2 (MT2) receptors have been found to increase gamma-aminobutyric acid (GABA) levels in several brain regions [45], and one study indicated that initiation of melatonin helped facilitate benzodiazepine discontinuation [46]. Further studies into the appropriate use and long-term side effects of melatonin use in cognitively impaired patients are required.

\section{Others}

Beta adrenergic receptor antagonists are sometimes used in the treatment in anxiety and have also been used to treat aggression in neuropsychiatric patients and patients with intellectual disabilities [47]. However, they have adverse side effects such as bradycardia and hypotension, and there is concern for limited efficacy and diminishing benefits over time [48]. Antihistaminergic medications are also used for anxiety but, owing to likely confusion and sedation, are clearly not preferred in the cognitively impaired or older population [28].

\section{Non-pharmacologic approaches}

Non-pharmacologic approaches to anxiety in the setting of cognitive impairment include cognitive therapies, behavioral therapies, cognitive-behavioral therapies, environmental approaches, and diet and exercise approaches. Strong studies of these approaches for comorbid anxiety and dementia are lacking; however, cognitive-behavioral approaches to anxiety in general have a strong evidence base and therefore seem promising for cognitively impaired patients if their level of functioning is such 
that they are able to participate in the treatment. Environmental approaches, including music, consistency in routine, orienting cues, distraction reduction, and appropriate level of stimulation, have been studied and have shown good effect for neuropsychiatric symptoms in general [49]. Diet and exercise approaches have less evidence but may have benefits because of improved health and increased activity.

Non-pharmacologic somatic treatments, in particular electroconvulsive therapy (ECT) and repetitive transcranial magnetic stimulation (rTMS), have been used and studied in geriatric populations. However, electroconvulsive therapy is not typically recommended for anxiety, and the role of rTMS for anxiety in any population is still unclear [50-52]. One possible exception is the established utility of ECT in Parkinson's disease with psychosis and comorbid anxiety, which was reported to be helpful in two cases [53].

\section{Conclusions}

Anxiety is a prevalent and impairing comorbidity among patients with cognitive disorders. Appropriate evaluation and work-up are necessary, followed by consideration of both non-pharmacologic and pharmacologic treatments. The combination of limited data and high risk of adverse effects makes treatment of anxiety difficult in the cognitively impaired and older populations. Difficulties in studying this population include typically advanced age, comorbid medical problems, frequently murky correlation between clinical signs and underlying pathology, concern for ability to obtain consent, medication interactions, concern for harm in placebo groups without active treatment, and difficulty obtaining an appropriately representative and significantly large sample size. Anxiety is also difficult to both study and treat in those who are not able to express themselves, as it can manifest quietly (internal anxiety that is not recognized by caregivers) or explosively (in aggressive violence or unusual behaviors). As older patients are less likely to report mental health problems, "quiet" anxiety may be missed; on the other hand, it is difficult to determine whether aggression and agitation are due to anxiety, and therefore it is difficult to draw conclusions about treatment of "explosive" anxiety. Further study into valid measures of differing types of anxiety in severely cognitively impaired patients, particularly in regard to neuropsychological evaluation and biomarkers, could lead to improved recognition and appropriate diagnosis.

Clinicians are currently able only to manage symptoms of neurodegenerative disorders; as reflected in this article, even these symptomatic treatments have limited evidence for use in anxiety. In practice, we often recommend use of cholinesterase inhibitors or memantine first because of indication for the primary disorder, relatively low side effect profile, and (particularly in the case of cholinesterase inhibitors) some evidence of positive effect on anxiety. If anxiety remains problematic, a trial of SSRIs or buspirone would be the next step. Benzodiazepines, beta-adrenergic antagonists, tricyclics, and antihistaminergic medications are often the last to be considered, because of side effect profiles, but may be useful in select cases with appropriate monitoring. The geriatric psychiatry mantra of "start low and go slow" is clearly applicable to this patient population. In addition to medications, environmental approaches, especially consistency in routine, orienting cues, appropriate level of stimulation, and evaluation of triggers, are recommended in almost all cases. Referral to psychotherapy is limited to patients who can participate appropriately.

Current research seeks the ultimate goal of diseasemodifying treatments, which are also the ultimate hope for treatment of neuropsychiatric symptoms such as anxiety. In the meantime, ongoing basic science research in both neurodegenerative and anxiety disorders, as well as clinical research into various pharmacologic and nonpharmacologic treatments, will hopefully improve insight into optimal treatment.

\section{Abbreviations}

AD, Alzheimer's disease; DICE, describe, investigate, collaborate, and evaluate; ECT, electroconvulsive therapy; GABA, gamma-aminobutyric acid; MCI, mild cognitive impairment; NPI, neuropsychiatric inventory; rTMS, repetitive transcranial magnetic stimulation; SSRI, selective serotonin reuptake inhibitor.

\section{Disclosures}

Anand Kumar receives grants from the National Institutes of Health and an honorarium from the American Journal of Geriatric Psychiatry as associate editor. Brian P. Gomoll declares that he has no disclosures.

\section{References}

I. Levenson RW, Sturm VE, Haase CM: Emotional and behavioral symptoms in neurodegenerative disease: a model for studying the neural bases of psychopathology. Annu Rev Clin Psychol 20I4, 28:58I-606.

2. Lyketsos CG, Lopez O, Jones B, Fitzpatrick AL, Breitner J, DeKosky S: Prevalence of neuropsychiatric symptoms in dementia and mild cognitive impairment: results from the cardiovascular health study. JAMA 2002, 288: |475-83.

3. Feldman $H$, Scheltens $P$, Scarpini E, Hermann $N$, Mesenbrink P, Mancione L, Tekin S, Lane R, Ferris S: Behavioral symptoms in mild cognitive impairment. Neurology 2004, 62: I I99-201.

FlOOOPrime RECOMMENDED

4. Dillon C, Serrano CM, Castro D, Leguizamón PP, Heisecke SL, Taragano FE: Behavioral symptoms related to cognitive impairment. Neuropsychiatr Dis Treat 2013, 9:|443-55. 
5. Palmer K, Berger AK, Monastero R, Winblad B, Bäckman L, Fratiglioni L: Predictors of progression from mild cognitive impairment to Alzheimer disease. Neurolog 2007, 68:1596-602.

\section{FlOOOPrime}

\section{RECOMMENDED}

6. Rabins PV, Schwartz S, Black BS, Corcoran C, Fauth E, Mielke M, Christensen J, Lyketsos C, Tschanz J: Predictors of progression to severe Alzheimer's disease in an incidence sample. Alzheimers Dement 2013, 9:204-7.

\section{FIOOOPRime}

7. Palmer K, Di lulio F, Varsi AE, Gianni W, Sancesario G, Caltagirone C, Spalletta G: Neuropsychiatric predictors of progression from amnestic-mild cognitive impairment to Alzheimer's disease: the role of depression and apathy. J Alzheimers Dis 2010, 20:175-83.

\section{FlOOOPrime}

RECOMMENDED

8. Taragano FE, Allegri RF: Mild behavioral impairment: the early diagnosis. Int Psychogeriatr 2003, I5(Suppl 2): 12.

9. Medina J, Weintraub S: Depression in primary progressive aphasia. J Geriatr Psychiatry Neurol 2007, 20:153-60.

\section{FlOOOPrime}

10. Rosen HJ, Allison SC, Ogar JM, Amici S, Rose K, Dronkers N, Miller BL, Gorno-Tempini ML: Behavioral features in semantic dementia vs other forms of progressive aphasias. Neurology 2006, 67:1752-6.

\section{FlOOOPrime}

\section{RECOMMENDED}

II. Porter VR, Buxton WG, Fairbanks LA, Strickland T, O'Connor SM, Rosenberg-Thompson S, Cummings JL: Frequency and characteristics of anxiety among patients with Alzheimer's disease and related dementias. J Neuropsychiatry Clin Neurosci 2003, I5:180-6.

\section{FIOOOPrime}

12. Etkin A: Neurobiology of anxiety: from neural circuits to novel solutions? Depress Anxiety 2012, 29:355-8.

13. Blay SL, Marinho V: Anxiety disorders in old age. Curr Opin Psychiatry 2012, 25:462-7.

14. Lissek S: Toward an account of clinical anxiety predicated on basic, neurally mapped mechanisms of Pavlovian fear-learning: the case for conditioned overgeneralization. Depress Anxiety 2012, 29:257-63.

15. Belzung C, Turiault M, Griebel G: Optogenetics to study the circuits of fear and depression-like behaviors: A critical analysis. Pharmacol Biochem Behav 2014, 122:144-57.

\section{FlOOOPrime \\ RECOMMENDED}

16. Hashimoto H, Monserratt L, Nguyen P: Anxiety and regional cortical glucose metabolism in patients with Alzheimer's disease. J Neuropsychiatry Clin Neurosci 2006, 18:521-8.

17. Monastero R, Mangialasche F, Camarda C, Ercolani S, Camarda R: A systematic review of neuropsychiatric symptoms in mild cognitive impairment. J Alzheimers Dis 2009, 18: I I-30.

\section{FlOOOPrime RECOMMENDED}

18. Adhikari A: Distributed circuits underlying anxiety. Front Behav Neurosci 2014, 8:112.

\section{FlOOOPrime}

\section{RECOMMENDED}

19. Balthazar ML, Pereira FR, Lopes TM, da Silva EL, Coan AC, Campos BM, Duncan NW, Stella F, Northoff G, Damasceno BP, Cendes F: Neuropsychiatric symptoms in Alzheimer's disease are related to functional connectivity alterations in the salience network. Hum Brain Mapp 20I4, 35:1237-46.

\section{FlOOOPrime}

20. Ferretti L, McCurry SM, Logsdon R, Gibbons L, Teri L: Anxiety and Alzheimer's disease. J Geriatr Psychiatry Neurol 200I, I4:52-8.

2I. Geda YE, Schneider LS, Gitlin LN, Miller DS, Smith GS, Bell J, Evans J, Lee $M$, Porsteinsson A, Lanctôt KL, Rosenberg PB, Sultzer DL, Francis PT, Brodaty H, Padala PP, Onyike CU, Ortiz LA, AncoliIsrael S, Bliwise DL, Martin JL, Vitiello MV, Yaffe K, Zee PC, Herrmann N, Sweet RA, Ballard C, Khin NA, Alfaro C, Murray PS, Schultz S, Lyketsos CG; Neuropsychiatric Syndromes Professional Interest Area of ISTAART: Neuropsychiatric symptoms in Alzheimer's disease: past progress and anticipation of the future. Alzheimers Dement 2013, 9:602-8.

\section{FlOOOPrime RECOMMENDED}

22. Kales HC, Gitlin LN, Lyketsos CG: The Detroit Expert Panel on the Assessment and Management of the Neuropsychiatric Symptoms of Dementia. Management of Neuropsychiatric Symptoms of Dementia in Clinical Settings: Recommendations from a Multidisciplinary Expert Panel. J Am Geriatr Soc 20I4, 62:762-9.

FlOOOPrime

23. Schulz R, Cook TB, Beach SR, Lingler JH, Martire LM, Monin JK, Czaja SJ: Magnitude and causes of bias among family caregivers rating Alzheimer disease patients. Am J Geriatr Psychiatry 2013, 21:14-25.

\section{FlOOOPrime
RECOMMENDED}

24. Cameron OG: The differential diagnosis of anxiety. Psychiatric and medical disorders. Psychiatr Clin North Am I985, 8:3-23.

25. Pollack M, Otto MW, Wittman CW, Rosenbaum JF: Anxious Patients. In Massachusetts General Hospital Handbook of General Hospital Psychiatry. 6th edition. Edited by Stern TA, Fricchione GL, Cassem NH, Jellinek MS, Rosenbaum JF. Philadelphia: Saunders Elsevier; 2010: I33-I52.

26. Starkman MN, Zelnik TC, Nesse RM, Cameron OG: Anxiety in patients with pheochromocytomas. Arch Intern Med 1985, 145:248-52.

FloOOPrime

RECOMMENDED

27. Chi S, Yu JT, Tan MS, Tan L: Depression in Alzheimer's disease: epidemiology, mechanisms, and management. J Alzheimers Dis 20।4, 42:739-55.

\section{FlOOOPrime}

\section{RECOMMENDED}

28. American Geriatrics Society 2012 Beers Criteria Update Expert Panel: American Geriatrics Society updated Beers Criteria for potentially inappropriate medication use in older adults. J Am Geriatr Soc. J Am Geriatr Soc 2012, 60:616-31.

\section{FlOOOPrime}

RECOMMENDED

29. Glass J, Lanctôt KL, Herrmann N, Sproule BA, Busto UE: Sedative hypnotics in older people with insomnia: metaanalysis of risks and benefits. BMJ 2005, 331:1169.

30. Pinquart $M$, Duberstein PR: Treatment of anxiety disorders in older adults: a meta-analytic comparison of behavioral and pharmacological interventions. Am J Geriatr Psychiatry 2007, 15:639-51.

3I. Trinh NH, Hoblyn J, Mohanty S, Yaffe K: Efficacy of cholinesterase inhibitors in the treatment of neuropsychiatric symptoms 
and functional impairment in Alzheimer disease: a metaanalysis. JAMA 2003, 289:210-6.

FlOOOPrime

32. Burt T: Donepezil and related cholinesterase inhibitors as mood and behavioral controlling agents. Curr Psychiatry Rep 2000, 2:473-8.

33. Gauthier S, Juby A, Dalziel W, Réhel B, Schecter R; EXPLORE investigators: Effects of rivastigmine on common symptomatology of Alzheimer's disease (EXPLORE). Curr Med Res Opin 2010, 26: I149-60.

34. Rosler M, Anand R, Cicin-Sain A, Gauthier S, Agid Y, Dal-Bianco P, Stähelin HB, Hartman R, Gharabawi M: Efficacy and safety of rivastigmine in patients with Alzheimer's disease: international randomised controlled trial. Br Med J 1999, 31 8:633-8.

35. Tariot PN, Solomon PR, Morris JC, Kershaw P, Lilienfeld S, Ding C: A 5-month, randomized, placebo-controlled trial of galantamine in AD. The Galantamine USA-I 0 Study Group. Neurology 2000, 54:2269-76.

36. Raskind MA, Peskind ER, Wessel T, Yuan W: Galantamine in AD: A 6-month randomized, placebo-controlled trial with a 6-month extension. Neurology 2000, 54:226I-8.

37. Mori E, Ikeda M, Kosaka K: Donepezil-DLB Study Investigators. Donepezil for dementia with Lewy bodies: a randomized, placebo-controlled trial. Ann Neurol 2012, 72:41-52.

38. Almaraz AC, Driver-Dunckley ED, Woodruff BK, Wellik KE, Caselli RJ, Demaerschalk BM, Adler CH, Caviness JN, Wingerchuk DM: Efficacy of rivastigmine for cognitive symptoms in Parkinson disease with dementia. Neurologist 2009, 15:234-7.

39. Minkeviciene $\mathrm{R}$, Banerjee $\mathrm{P}$, Tanila $\mathrm{H}$ : Cognition-enhancing and anxiolytic effects of memantine. Neuropharmacology 2008, 54:1079-85.

40. Smith EG, Deligiannidis KM, Ulbricht CM, Landolin CS, Patel JK, Rothschild AJ: Antidepressant augmentation using the $\mathrm{N}$-methyl-D-aspartate antagonist memantine: a randomized, double-blind, placebo-controlled trial. J Clin Psychiatry 2013, 74:966-73.

41. Cantillon M, Brunswick R, Molina D, Bahro, M: Buspirone vs. haloperidol. A double-blind trial for agitation in nursing home population with Alzheimer's disease. Am J Geriatr Psychiatry 1996, 4:263-7.

42. Loane C, Politis M: Buspirone: what is it all about? Brain Res 2012, 2I;| I46I:III-8.
43. Cooper JP: Buspirone for anxiety and agitation in dementia. J Psychiatry Neurosci 2003, 28:469.

44. McCleery J, Cohen DA, Sharpley AL: Pharmacotherapies for sleep disturbances in Alzheimer's disease. Cochrane Database Syst Rev 2014, 3:CD009178.

FlOOOPrime

RECOMMENDED

45. Comai S, Gobbi G: Unveiling the role of melatonin MT2 receptors in sleep, anxiety and other neuropsychiatric diseases: a novel target in psychopharmacology. J Psychiatry Neurosci 2014, 39:6-2I

FIOOOPrime

46. Garfinkel D, Zisapel N, Wainstein J, Laudon M: Facilitation of benzodiazepine discontinuation by melatonin: a new clinical approach. Arch Intern Med 1999, 159:2456-60.

47. Silver JM, Yudofsky SC, Anderson KE: Agitation and aggression. In Guide to Neuropsychiatric Therapeutics. Edited by Coffey CE, McAllister TW, Silver JM. Philadelphia: Lippincott Williams \& Wilkins; 2007: 37I-87.

48. Blay SL, Marinho V: Anxiety disorders in old age. Curr Opin Psychiatry 2012, 25:462-7.

49. Lyketsos CG, Carrillo MC, Ryan JM, Khachaturian AS, Trzepacz P, Amatniek J, Cedarbaum J, Brashear R, Miller DS: Neuropsychiatric symptoms in Alzheimer's disease. Alzheimers Dement 201 I, 7:532-9.

\section{FlOOOPrime} RECOMMENDED

50. Pallanti S, Bernardi S: Neurobiology of repeated transcranial magnetic stimulation in the treatment of anxiety: a critical review. Int Clin Psychopharmacol 2009, 24:163-73.

5I. Paes F, Machado S, Arias-Carrión O, Velasques B, Teixeira S, Budde H, Cagy M, Piedade R, Ribeiro P, Huston JP, Sack AT, Nardi AE: The value of repetitive transcranial magnetic stimulation (rTMS) for the treatment of anxiety disorders: an integrative review. CNS Neurol Disord Drug Targets 20I I, 10:610-20.

52. Cristancho MA, Cristancho P, O'Reardon JP: Other therapeutic psychiatric uses of superficial brain stimulation. Handb Clin Neurol 2013, 116:415-22.

53. Marino L, Friedman JH: Letter to the editor: successful use of electroconvulsive therapy for refractory anxiety in Parkinson's disease. Int J Neurosci 2013, I 23:70-I.

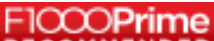

RECOMMENDED 